\title{
Orthostatic Hypotension Following Posterior Spinal Fusion Surgeries for Spinal Deformity Correction in Adolescents: Prevalence and Risk Factors
}

\section{Ying Yang}

Peking Union Medical College Hospital

\section{Yaping Chen}

Peking Union Medical College Hospital

\section{Bingdu Tong}

Peking Union Medical College Hospital

\section{Xue Tian}

Peking Union Medical College Hospital

\section{Chunjie Yu}

Peking Union Medical College Hospital

\section{Zhe Su}

Peking Union Medical College Hospital

Jianguo Zhang ( $\nabla$ jgzhang_pumch@yahoo.com )

Peking Union Medical College Hospital

\section{Research Article}

Keywords: orthostatic hypotension $(\mathrm{OH})$, spinal deformity, laminectomy, osteotomy

Posted Date: June 24th, 2021

DOl: https://doi.org/10.21203/rs.3.rs-618724/v1

License: (c) (i) This work is licensed under a Creative Commons Attribution 4.0 International License. Read Full License

Version of Record: A version of this preprint was published at BMC Musculoskeletal Disorders on December 1st, 2021. See the published version at https://doi.org/10.1186/s12891-021-04931-0. 


\section{Abstract}

Study Design: Retrospective case series.

Objectives: This study aimed to determine the prevalence and risk factors for orthostatic hypotension $(\mathrm{OH})$ in adolescents undergoing posterior spinal fusion for spinal deformity correction.

Methods: The data of 312 consecutive adolescents who underwent posterior spinal fusion for spinal deformity correction in our center over 12 months were retrieved. Patient characteristics, including whether laminectomy or osteotomy was performed during the surgery, the occurrence of postoperative nausea and vomiting (PONV), perioperative hemoglobin albumin changes, perioperative blood transfusion, length of bed rest, willingness to ambulate, length of postoperative exercises of the lower limbs, and length of hospital stay, were collected and compared statistically between patients who did and did not develop postoperative $\mathrm{OH}$.

Results: Of 312 patients, 225 (72.1\%) developed OH postoperatively, and all cases completely resolved 5 days after the first out-of-bed exercises. Significant differences in BMI, the incidence of PONV, the willingness to ambulate and the length of postoperative exercises of the lower limbs were observed. The mean length of hospital stay of the patients with $\mathrm{OH}$ was longer than that of the patients without $\mathrm{OH}$.

Conclusion: Our study suggests that temporary $\mathrm{OH}$ is a common manifestation following posterior spinal fusion for spinal deformity correction in adolescents. Postoperative $\mathrm{OH}$ may increase the length of hospital stay in these patients. Patients with PONV, who are not willing to ambulate and who perform postoperative lower limb exercises for a shorter time are more likely to have $\mathrm{OH}$.

\section{Introduction}

Orthostatic hypotension $(\mathrm{OH})$, which is when a patient's blood pressure falls when moving from a supine position to a standing position, is a common cardiovascular disorder. It is defined as a decrease in the systolic blood pressure (BP) by more than $20 \mathrm{mmHg}$ or a decrease in the diastolic BP be more than 10 $\mathrm{mmHg}$ from the baseline BP within 3 minutes of changing the body position from a supine position to an upright posture (1). Postoperative $\mathrm{OH}$ is a common manifestation following various surgeries, and its etiology is multifactorial and may vary according to the type of surgery $(2,3)$. Postoperative $\mathrm{OH}$ is often characterized by symptoms of syncope, dizziness, and light headedness. However, weakness, fatigue, cognitive issues, visual blurring, headache, neck pain, orthostatic dyspnea, or chest pain caused by $\mathrm{OH}$ may also occur in some patients and make patients distressed, potentially delaying recovery after surgery $(4,5)$. An association between $\mathrm{OH}$ and many types of surgeries, including cervical spine surgery, has been reported $(3,6,7)$. However, to date, no studies have studied the association between $\mathrm{OH}$ and posterior spinal fusion surgeries for the treatment of adolescent spinal deformities. We conducted this study to evaluate the prevalence and risk factors for $\mathrm{OH}$ in adolescent patients undergoing posterior spinal fusion for spinal deformity correction. 


\section{Methods}

After institutional review board approval was received, all adolescent patients who had undergone posterior spinal fusion surgery under general anesthesia for spinal deformity correction from March 2019 to June 2020 were enrolled. The inclusion criteria were as follows: 1) patients who underwent posterior fusion surgery for spinal deformity correction; 2) patients aged between 10 years and 20 years; 3 ) patients without dura tears during surgery; 4) patients without a history of $\mathrm{OH}$; and 5) patients without a history of neuromuscular disease or neurological deficits. All patients were asked to perform early ambulation and stand within 72 hours after surgery. Postoperative $\mathrm{OH}$ was observed and recorded. The SRS-22 questionnaire was used to evaluate function at 3 months after surgery.

The inpatient records were reviewed for patient characteristics such as age, sex, body mass index (BMI), the number of levels instrumented and fused, whether laminectomy or osteotomy was performed during the surgery, the occurrence of postoperative nausea and vomiting (PONV), perioperative hemoglobin albumin changes, perioperative blood trans fusion, the length of bed rest, the willingness to ambulate, the length of postoperative exercises of the lower limbs, and the length of hospital stay.

Statistical analysis was performed using IBM SPSS Statistics (version 22.0), and significance tests were 2 -sided at $5 \%$. The results are expressed as means and SDs for the continuous variables and frequencies for the categorical variables. The $P$ values were calculated using independent-samples $t$ tests or nonparametric tests. For the categorical variables, the chi-square or Fisher's exact test was used. Binary logistic regression analysis was used to identify the risk factors affecting postoperative $\mathrm{OH}$. The significance level was set at $a=0.05$.

\section{Results}

Three hundred and twelve patients were enrolled. None of them had perioperative neurological deficits. There were 191 males and 121 males. The mean age was $15.5 \pm 4.8$ (10-20) years, and postoperative $\mathrm{OH}$ occurred in 225 (72.1\%) patients. Most postoperative $\mathrm{OH}$ cases occurred within 2 days after the patient started standing from bed. All $\mathrm{OH}$ cases completely resolved after the fifth day of standing (Fig. 1). One hundred ninety patients developed $\mathrm{OH}$ the first time they stood postoperatively. Among the 122 patients who did not develop $\mathrm{OH}$ the first time they stood postoperatively, 35 developed $\mathrm{OH}$ when standing from the supine position on a subsequent day (Table 1). 
Table 1

Timing of the postoperative $\mathrm{OH}$

\begin{tabular}{|lll|}
\hline OH occurred at the time of 1st postoperative standing & & \\
\hline Duration of $\mathrm{OH}(\leq 2$ days) & 175 & $92.11 \%$ \\
\hline Duration of $\mathrm{OH}(\mathbf{2}$ 2days) & 15 & $7.89 \%$ \\
\hline Without $\mathrm{OH}$ at the time of 1st postoperative standing & & \\
\hline Without $\mathrm{OH}$ until discharge & 87 & $71.31 \%$ \\
\hline OH occurred during the following Days & 35 & $28.69 \%$ \\
\hline
\end{tabular}

A t test or chi-square test was performed to compare the variables between patients with and without postoperative $\mathrm{OH}$. There were no significant differences in age, sex, the number of levels instrumented and fused, whether laminectomy or osteotomy was performed during the surgery, perioperative hemoglobin albumin changes, perioperative blood transfusion or the length of bed rest. Significant differences were found in the occurrence of PONV $(P=0.008)$, willingness to ambulate $(P=0.000)$, length of postoperative exercises of the lower limbs $(P=0.000)$ and $B M I(P=0.001)$. The mean length of hospital stay of the patients with $\mathrm{OH}$ was longer than that of the patients without $\mathrm{OH}(P=0.002)$. No significant differences were found in the SRS-22 score at 3 months after surgery $(P=0.638)$ (Table 2$)$. 
Table 2

Comparison between patients with and without postoperative $\mathrm{OH}$

\begin{tabular}{|c|c|c|c|c|c|c|}
\hline & $\begin{array}{l}\text { Cases } \\
(\mathrm{n})\end{array}$ & With $\mathrm{OH}$ & $\begin{array}{l}\text { Without } \\
\mathrm{OH}\end{array}$ & $\begin{array}{l}\text { Incidence } \\
\text { of } \mathrm{OH}\end{array}$ & $x^{2} / t$ & $\begin{array}{l}\mathrm{P} \\
\text { value }\end{array}$ \\
\hline \multicolumn{7}{|l|}{ Gender } \\
\hline Male & 191 & 131 & 60 & $68.59 \%$ & \multirow[t]{2}{*}{3.050} & \multirow[t]{2}{*}{0.081} \\
\hline Female & 121 & 94 & 27 & $77.68 \%$ & & \\
\hline \multicolumn{7}{|l|}{ o Occurrence of PONV } \\
\hline+ & 145 & 128 & 17 & $88.28 \%$ & \multirow[t]{2}{*}{6.974} & \multirow[t]{2}{*}{0.008} \\
\hline- & 167 & 97 & 70 & $58.08 \%$ & & \\
\hline \multicolumn{7}{|l|}{ Ambulation willingness } \\
\hline+ & 202 & 119 & 83 & $58.9 \%$ & \multirow[t]{2}{*}{49.678} & \multirow[t]{2}{*}{0.000} \\
\hline- & 110 & 106 & 4 & $96.36 \%$ & & \\
\hline \multicolumn{7}{|l|}{ Blood transfusion } \\
\hline+ & 79 & 61 & 18 & $77.22 \%$ & \multirow[t]{2}{*}{1.368} & \multirow[t]{2}{*}{0.242} \\
\hline- & 233 & 164 & 69 & $70.39 \%$ & & \\
\hline \multicolumn{7}{|c|}{$\begin{array}{l}\text { Length of postoperative Lower- } \\
\text { limb exercise }\end{array}$} \\
\hline $0-15 \mathrm{~min} / \mathrm{d}$ & 157 & 153 & 4 & $97.45 \%$ & \multirow[t]{3}{*}{138.445} & \multirow[t]{3}{*}{0.000} \\
\hline $15-30 \mathrm{~min} / \mathrm{d}$ & 103 & 64 & 39 & $62.14 \%$ & & \\
\hline$>30 \mathrm{~min} / \mathrm{d}$ & 52 & 8 & 44 & $15.38 \%$ & & \\
\hline Length of staying in bed(h) & & $\begin{array}{l}62.44 \pm \\
11.93\end{array}$ & $\begin{array}{l}61.75 \pm \\
8.35\end{array}$ & & -0.957 & 0.339 \\
\hline Age(years) & & $\begin{array}{l}12.24 \pm \\
5.14\end{array}$ & $\begin{array}{l}11.49 \pm \\
1.68\end{array}$ & & -1.324 & 0.187 \\
\hline Height(cm) & & $\begin{array}{l}1.53 \pm \\
0.15\end{array}$ & $\begin{array}{l}1.55 \pm \\
0.24\end{array}$ & & 0.481 & 0.631 \\
\hline Weight(kg) & & $\begin{array}{l}40.37 \pm \\
16.77\end{array}$ & $\begin{array}{l}37.73 \pm \\
10.08\end{array}$ & & -1.892 & 0.059 \\
\hline Body mass index & & $\begin{array}{l}18.89 \pm \\
3.31\end{array}$ & $\begin{array}{l}14.49 \pm \\
2.79\end{array}$ & & -3.480 & 0.001 \\
\hline $\begin{array}{l}\text { HGB decrease value } \\
(\mathrm{g} / \mathrm{L})\end{array}$ & & $\begin{array}{l}29.94 \pm \\
9.94\end{array}$ & $\begin{array}{l}29.10 \pm \\
10.13\end{array}$ & & -0.590 & 0.556 \\
\hline
\end{tabular}




\begin{tabular}{|c|c|c|c|c|c|c|}
\hline & $\begin{array}{l}\text { Cases } \\
\text { (n) }\end{array}$ & With $\mathrm{OH}$ & $\begin{array}{l}\text { Without } \\
\mathrm{OH}\end{array}$ & $\begin{array}{l}\text { Incidence } \\
\text { of } \mathrm{OH}\end{array}$ & $\mathrm{x}^{2} / \mathrm{t}$ & $\begin{array}{l}P \\
\text { value }\end{array}$ \\
\hline $\begin{array}{l}\text { ALB decrease value } \\
(\mathrm{g} / \mathrm{L})\end{array}$ & & $\begin{array}{l}9.64 \pm \\
3.29\end{array}$ & $\begin{array}{l}9.58 \pm \\
3.55\end{array}$ & & -0.147 & 0.883 \\
\hline $\begin{array}{l}\text { Surgical duration } \\
\text { (min) }\end{array}$ & & $\begin{array}{l}226.4 \pm \\
60.71\end{array}$ & $\begin{array}{l}229.02 \pm \\
54.32\end{array}$ & & 0.34 & 0.734 \\
\hline Number of fusion segments & & $\begin{array}{l}8.45 \pm \\
3.81\end{array}$ & $\begin{array}{l}8.76 \pm \\
4.17\end{array}$ & & 0.616 & 0.538 \\
\hline Hospital Stay & & $\begin{array}{l}11.55 \pm \\
3.43\end{array}$ & $\begin{array}{l}8.13 \pm \\
3.45\end{array}$ & & 29.315 & 0.002 \\
\hline SRS-22 score & & $\begin{array}{l}4.3 \pm \\
1.73\end{array}$ & $4.4 \pm 1.32$ & & 0.783 & 0.638 \\
\hline
\end{tabular}

Binary logistic regression was used to evaluate the risk factors for $\mathrm{OH}$ that had been identified with the $\mathrm{t}$ test or chi-square test. The occurrence of PONV, willingness to ambulate, and time of postoperative exercises of the lower limbs were found to be significantly associated with postoperative $\mathrm{OH}$ (Table 3).

Table.3 Risk factors of $\mathrm{OH}($ Binary logistic regression)

\begin{tabular}{|c|c|c|c|c|c|c|c|}
\hline \multirow[t]{2}{*}{ Factors } & \multirow[t]{2}{*}{$\begin{array}{l}\text { Regression } \\
\text { coefficients }\end{array}$} & \multirow[t]{2}{*}{$\begin{array}{l}\text { Standard } \\
\text { error }\end{array}$} & \multirow[t]{2}{*}{ Wald } & \multirow[t]{2}{*}{$\mathbf{P}$} & \multirow[t]{2}{*}{$\begin{array}{l}\text { Odds } \\
\text { ratio }\end{array}$} & \multicolumn{2}{|c|}{$\begin{array}{l}95 \% \\
\text { Confifidence } \\
\text { Interval }\end{array}$} \\
\hline & & & & & & Upper & $\begin{array}{l}\text { Lower } \\
\text { I }\end{array}$ \\
\hline Constant & 6.514 & 1.658 & 15.433 & 0.000 & -- & & \\
\hline PONV & 1.465 & 0.451 & 10.538 & 0.001 & 4.327 & 1.787 & 10.479 \\
\hline $\begin{array}{l}\text { Ambulation } \\
\text { willingness }\end{array}$ & -2.678 & 0.590 & 20.623 & 0.000 & 0.069 & 0.022 & 0.218 \\
\hline $\begin{array}{l}\text { Lower limb } \\
\text { exercise time }\end{array}$ & -2.386 & 0.345 & 47.721 & 0.000 & 0.092 & 0.047 & 0.181 \\
\hline Body mass index & 0.026 & 0.077 & 0.117 & 0.732 & 1.027 & 0.883 & 1.194 \\
\hline
\end{tabular}

\section{Discussion}

$\mathrm{OH}$ is a common cardiovascular disorder whose clinical significance is increasingly being recognized, as $\mathrm{OH}$ can decrease quality of life and potentially worsen prognoses $(8,9)$. OH has been well studied and is closely associated with other common chronic diseases, including hypertension, congestive heart failure, 
diabetes mellitus, and Parkinson's disease. The prevalence of $\mathrm{OH}$ in patients older than 65 years of age was found to be approximately $20 \%(10)$.

Most previous studies on $\mathrm{OH}$ were population-based cohort studies or performed in elderly individuals $(11,12)$. However, there are few studies on $\mathrm{OH}$ in hospitalized patients. Hospitalized patients are particularly vulnerable to the consequences of $\mathrm{OH}$, particularly falls, because postural $\mathrm{BP}$ regulation may be disturbed by many common acute illnesses as well as by bed rest and drug treatment $(2,13)$. Feldstein reported that $\mathrm{OH}$ occurred in as many as $60 \%$ of hospitalized adults. Acute physiological and psychological changes due to illness, surgery and anesthesia occur in patients who undergo surgery. Postoperative $\mathrm{OH}$ has been well-documented (2). Hanada et al found that approximately $40 \%$ of 195 patients undergoing cardiothoracic and abdominal surgery experience $\mathrm{OH}$ during early postoperative mobilization (7).

Early mobilization is important after major orthopedic surgery to prevent morbidities and long hospital stays. Postoperative $\mathrm{OH}$ can prevent early mobilization and has been observed in patients undergoing major orthopedic surgeries. Postoperative $\mathrm{OH}$ can lead to failed physiotherapy in patients who have undergone hip arthroplasty, and its incidence has been reported to be $40 \%-50 \%(6,14)$. Associations between $\mathrm{OH}$ and spine surgeries and spinal cord injuries have also been found. Edward et al found that 22 of 190 patients who underwent cervical spine surgery (11.6\%) developed postoperative $\mathrm{OH}$. The authors found that the presence of neurological deficits is a risk factor for postoperative $\mathrm{OH}$ (3). The link between spinal cord injuries (SCls) and the development of $\mathrm{OH}$ has been observed (15). Postural changes during physiotherapy and mobilization have been shown to induce clinically significant $\mathrm{OH}$ in $74 \%$ of $\mathrm{SCl}$ patients, with symptoms in 59\% of patients (15). Significant differences in the incidence of $\mathrm{OH}$ between patients with compressive cervical myelopathy and healthy controls were found in Srihari's study (16). Furthermore, McKinley et al found that traumatic SCl patients had a significantly higher incidence of $\mathrm{OH}$ than did nontraumatic SCI patients (36.7\% vs $5.3 \%)(17)$.

Previous studies have shown that early ambulation can decrease the length of hospital stay and perioperative complications and improve functional outcomes in adolescent and adult patients undergoing correction surgery for spinal deformities $(18,19)$. Thus, we asked patients in this group to perform out-of-bed exercises and stand within 72 hours after surgery. Postoperative $\mathrm{OH}$ may occur and affect recovery in these patients. However, until now, there have been no studies on postoperative $\mathrm{OH}$ following posterior spinal fusion surgeries for spinal deformity correction in adolescents. In the current study, we determined the incidence of postoperative $\mathrm{OH}$ following posterior spinal fusion for the treatment of adolescent spinal deformities. Two hundred and twenty-five $(72.1 \%)$ of 312 adolescent patients who underwent correction surgeries for spinal deformities and performed out-of-bed exercises early and stood within 72 hours after surgery developed postoperative $\mathrm{OH}$, which mostly occurred within 2 days of standing, and all cases completely resolved after the fifth day of standing. The presence of postoperative $\mathrm{OH}$ significantly increased the length of hospital stay. However, no differences in the SRS22 score were found between the patients with and without postoperative $\mathrm{OH}$. 
The risk factors for postoperative $\mathrm{OH}$ following spine surgeries remain unclear. Neurological deficits and traumatic $\mathrm{SCl}$ have been reported to be associated with a higher incidence of postoperative $\mathrm{OH}$ (3). In our study, we found that age, sex, the number of levels instrumented and fused, whether laminectomy or osteotomy was performed during the surgery, the postoperative hemoglobin level and the postoperative albumin level were not significantly associated with postoperative $\mathrm{OH}$ following posterior spinal fusion surgeries for the correction of spinal deformities in adolescent patients. Significant associations between PONV, willingness to ambulate, length of postoperative exercises of the lower limbs and postoperative $\mathrm{OH}$ were found. The association between PONV and $\mathrm{OH}$ was reported in a previous study. Franz et al found that female patients with preoperative $\mathrm{OH}$ had an increased risk of PONV (20). For patients with risk factors for PONV, including the female sex, a history of motion sickness or previous PONV, a nonsmoking status, and the use of postoperative opioid drugs, therapies should be given to decrease the occurrence or severity of PONV and postoperative $\mathrm{OH}$. Early postoperative exercise, including lower limb strength training, is an essential component of rehabilitation protocols following posterior spinal fusion surgeries and can improve function and shorten the hospital stay (21-23). According to our findings, better patient education of early postoperative ambulation to encourage patients to perform early postoperative out-ofbed exercises and postoperative strategies to increase the mobility of the lower limbs may be helpful to decrease the incidence of postoperative $\mathrm{OH}$ following posterior spinal fusion surgeries for the treatment of adolescent spinal deformities.

\section{Conclusion}

Temporary $\mathrm{OH}$ is a common manifestation following posterior spinal fusion for spinal deformity correction in adolescents, and all patients' $\mathrm{OH}$ completely resolved after the fifth day of out-of-bed activity. Postoperative $\mathrm{OH}$ may increase the length of hospital stay in these patients. Patients with PONV, who are not willing to perform out-of-bed exercises and perform postoperative lower limb exercises for a shorter time are more likely to have postoperative $\mathrm{OH}$. Hence, we suggest that postural BP should be routinely monitored in this group of patients so that early intervention can be initiated. Strategies to prevent PONV, to improve patients' willingness to ambulate and to increase the length of postoperative lower limb exercises may be helpful to decrease the occurrence of postoperative $\mathrm{OH}$ in these patients.

\section{Declarations}

\section{Acknowledgements}

None.

\section{Authors'contributions}

Y.Y. and Z.S. wrote the main manuscript text. Y.C. and X.T. prepared figure 1. B.T., Y.C. and C.Y. prepared table 1-3. Y.Y. and J.Z. provided the clinical material. All authors reviewed the manuscript.

\section{Funding}


The study was supported by grants from National Natural Science Foundation of China (81972037).

\section{Availability of data and materials}

The datasets generated and analyzed during the current study are not publicly available due risk of compromising individual privacy but are available from the corresponding author on reasonable request.

\section{Ethics approval and consent to participate}

Approval for the study was obtained from the ethics committee at Peking Union Medical College Hospital. Due to the retrospective nature of this research, exemption of informed consent was granted by the ethics committee at Peking Union Medical College Hospital. The authors confirmed that all methods were performed in accordance with the relevant guidelines and regulations.

\section{Consent for publication}

Not applicable.

\section{Competing interests}

The authors declare that they have no competing interest.

IRB Approval Statement. This study has been approved from the Institutional Review Board.

\section{References}

1. Freeman R, Wieling W, Axelrod FB, Benditt DG, Benarroch E, Biaggioni I, et al. Consensus statement on the definition of orthostatic hypotension, neurally mediated syncope and the postural tachycardia syndrome. Clin Auton Res. 2011;21(2):69-72.

2. Feldstein $C$, Weder AB. Orthostatic hypotension: a common, serious and underrecognized problem in hospitalized patients. J Am Soc Hypertens. 2012;6(1):27-39.

3. Ong ET, Yeo LK, Kaliya-Perumal AK, Oh JY. Orthostatic Hypotension Following Cervical Spine Surgery: Prevalence and Risk Factors. Global Spine J. 2020;10(5):578-82.

4. Lanier JB, Mote MB, Clay EC. Evaluation and management of orthostatic hypotension. Am Fam Physician. 2011;84(5):527-36.

5. Palma JA, Kaufmann H. Management of Orthostatic Hypotension. Continuum (Minneap Minn). 2020;26(1):154-77.

6. Jans $\emptyset$, Bundgaard-Nielsen M, Solgaard S, Johansson PI, Kehlet H. Orthostatic intolerance during early mobilization after fast-track hip arthroplasty. $\mathrm{Br} \mathrm{J}$ Anaesth. 2012;108(3):436-43.

7. Hanada M, Tawara Y, Miyazaki T, Sato S, Morimoto Y, Oikawa M, et al. Incidence of orthostatic hypotension and cardiovascular response to postoperative early mobilization in patients undergoing cardiothoracic and abdominal surgery. BMC Surg. 2017;17(1):111. 
8. Ricci F, De Caterina R, Fedorowski A. Orthostatic Hypotension: Epidemiology, Prognosis, and Treatment. J Am Coll Cardiol. 2015;66(7):848-60.

9. Kanjwal K, George A, Figueredo VM, Grubb BP. Orthostatic hypotension: definition, diagnosis and management. J Cardiovasc Med (Hagerstown). 2015;16(2):75-81.

10. Magkas N, Tsioufis C, Thomopoulos C, Dilaveris P, Georgiopoulos G, Sanidas E, et al. Orthostatic hypotension: From pathophysiology to clinical applications and therapeutic considerations. J Clin Hypertens (Greenwich). 2019;21(5):546-54.

11. Hiitola P, Enlund H, Kettunen R, Sulkava R, Hartikainen S. Postural changes in blood pressure and the prevalence of orthostatic hypotension among home-dwelling elderly aged 75 years or older. J Hum Hypertens. 2009;23(1):33-9.

12. Villavicencio-Chávez C, Miralles Basseda R, González Marín P, Cervera AM. [Orthostatic and postprandial hypotension in elderly patients with chronic diseases and disability: prevalence and related factors]. Rev Esp Geriatr Gerontol. 2009;44(1):12-8.

13. Rhebergen GA, Schölzel-Dorenbos CJ. [Orthostatic and postprandial hypotension in patients aged 70 years or older admitted to a medical ward]. Tijdschr Gerontol Geriatr. 2002;33(3):119-23.

14. Jans $\varnothing$, Mehlsen J, Kjærsgaard-Andersen P, Husted H, Solgaard S, Josiassen J, et al. Oral Midodrine Hydrochloride for Prevention of Orthostatic Hypotension during Early Mobilization after Hip Arthroplasty: A Randomized, Double-blind, Placebo-controlled Trial. Anesthesiology. 2015;123(6):1292-300.

15. Illman A, Stiller K, Williams M. The prevalence of orthostatic hypotension during physiotherapy treatment in patients with an acute spinal cord injury. Spinal Cord. 2000;38(12):741-7.

16. Srihari G, Shukla D, Indira Devi B, Sathyaprabha TN. Subclinical autonomic nervous system dysfunction in compressive cervical myelopathy. Spine (Phila Pa 1976). 2011;36(8):654-9.

17. McKinley WO, Tewksbury MA, Godbout CJ. Comparison of medical complications following nontraumatic and traumatic spinal cord injury. J Spinal Cord Med. 2002;25(2):88-93.

18. Adogwa O, Elsamadicy AA, Fialkoff J, Cheng J, Karikari IO, Bagley C. Early Ambulation Decreases Length of Hospital Stay, Perioperative Complications and Improves Functional Outcomes in Elderly Patients Undergoing Surgery for Correction of Adult Degenerative Scoliosis. Spine (Phila Pa 1976). 2017;42(18):1420-5.

19. Fletcher ND, Andras LM, Lazarus DE, Owen RJ, Geddes BJ, Cao J, et al. Use of a Novel Pathway for Early Discharge Was Associated With a 48\% Shorter Length of Stay After Posterior Spinal Fusion for Adolescent Idiopathic Scoliosis. J Pediatr Orthop. 2017;37(2):92-7.

20. Pusch F, Berger A, Wildling E, Zimpfer M, Moser M, Sam C, et al. Preoperative orthostatic dysfunction is associated with an increased incidence of postoperative nausea and vomiting. Anesthesiology. 2002;96(6):1381-5.

21. Liu SK, Song YL, Ding WY, Yang DL, Ma L, Yang SD. The effect of systematic lower-limb rehabilitation training in elderly patients undergoing lumbar fusion surgery: a retrospective study. Oncotarget. 2017;8(68):112720-6. 
22. Wang H, Huo Y, Zhao Y, Zhang B, Yang D, Yang S, et al. Clinical Rehabilitation Effect of Postoperative Lower-Limb Training on the Patients Undergoing OLIF Surgery: A Retrospective Study. Pain Res Manag. 2020;2020:1065202.

23. Tarnanen S, Neva MH, Dekker J, Häkkinen K, Vihtonen K, Pekkanen L, et al. Randomized controlled trial of postoperative exercise rehabilitation program after lumbar spine fusion: study protocol. BMC Musculoskelet Disord. 2012;13:123.

\section{Figures}

\section{Occurrence of $\mathrm{OH}$}

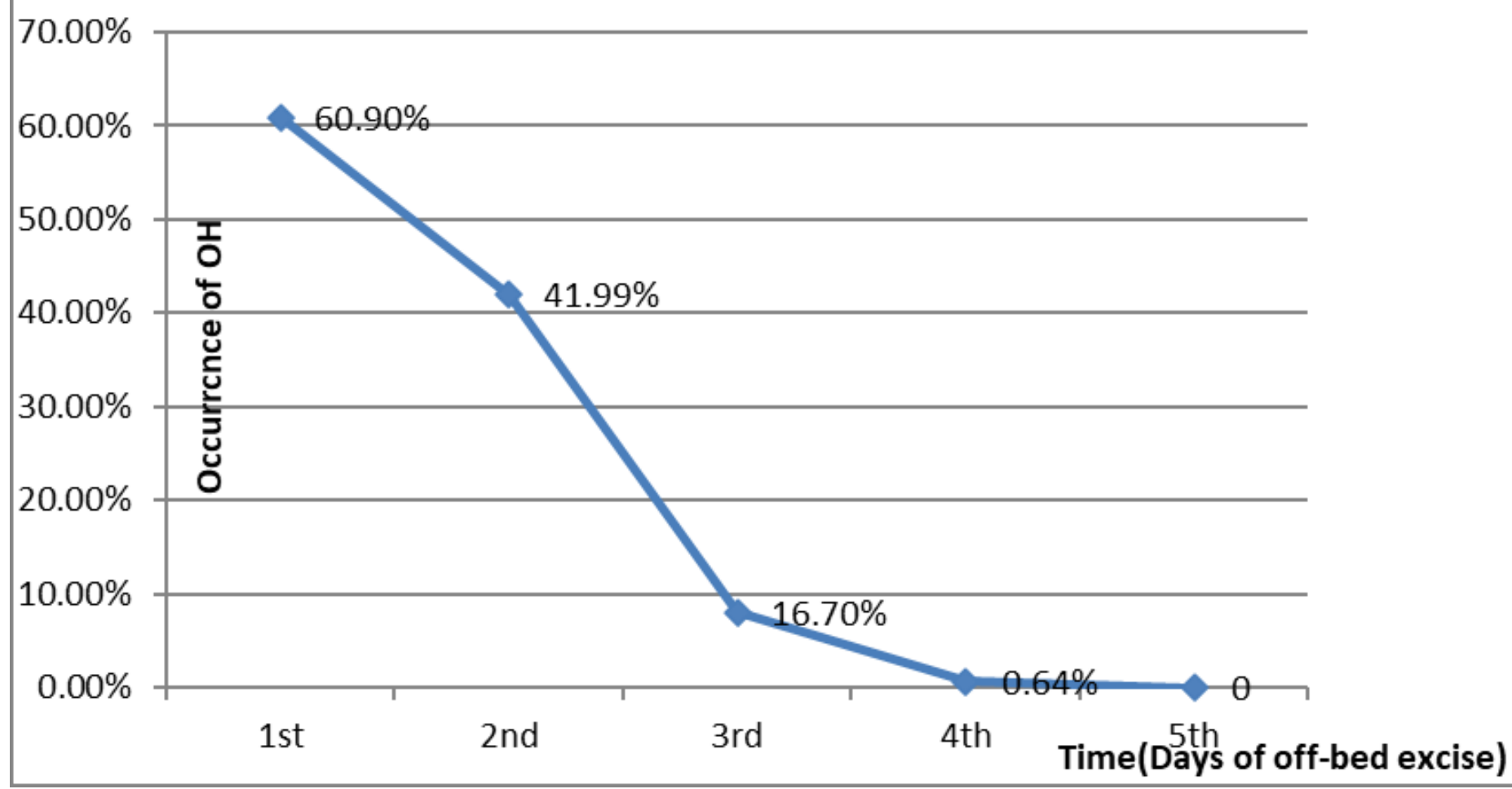

Figure 1

Most postoperative $\mathrm{OH}$ cases occurred within 2 days after standing from bed. All $\mathrm{OH}$ cases completely resolved after the fifth day of standing. 